— ORIGINAL ARTICLE

Volume 8 Issue 12016

D0l: 10.5959/eimj.v8i1.408

ARTICLE INFO

Submitted: $30-11-2015$

Accepted: 10-03-2016

\section{How Do Medical Students Learn at Ibn Sina National College for Medical Studies in Jeddah, KSA? Assessment of Student's Learning Styles}

\author{
Hani Atwa ${ }^{1,2}$, Enjy Abozeid', Sally Fouad' \\ ${ }^{1}$ Medical Education Department, Faculty of Medicine, Suez Canal \\ University, Egypt \\ ${ }^{2}$ Ibn Sina National College for Medical Studies, Feddah, Saudi Arabia
}

ABSTRACT

Background: An important preliminary step in learning and teaching planning is the understanding of your learner. This understanding will help in the allocation of instructional methods and curriculum development. Understanding the learner enfolds the understanding of different learner characteristics. One of these characteristics to be is the learning styles. Aim: This study aims to explore learning styles of medical students at Ibn Sina National College for Medical Studies (ISNC) and determine the effect of related factors as gender, as well as making recommendations to improve teaching and learning at the College. Subjects and Methods: Barsch Learning Styles Inventory was used to assess the learning styles of the MBBS students at ISNC. A sample size of 550 students has been targeted. The overall response rate was $82.7 \%(n=455)$. Scores have been manually calculated for each student and his/her learning style is indicated based on the inventory manual. Descriptive statistics were applied, and statistical significance was set at $p<0.05$. Results: Visual Learning Style is the common style among the studies sample of students. However, participants were found to use more than one learning styles (two or three styles) for taking in information. There were minor differences between males and females in styles' prevalence. Those differences were not statistically significant. Conclusion: The most prevalent learning style is the visual one, which is in agreement with the literature on learning styles. The prevalence of different styles is similar in both males and females.

Keywords: Learning styles, Barsch Learning Inventory, Ibn Sina College in feddah

CORRESPONDING AUTHOR Dr. Hani Atwa, Medical Education Department, Faculty of Medicine, Suez Canal University, Ismailia 41611, Egypt | Email: doctorhani2000@yahoo.com

\section{Introduction}

An important preliminary step in learning and teaching planning is deeply understanding of your learner. This analysis and understanding will help in the allocation of the instructional methods and the curriculum development. Understanding the learner enfolds the understanding of different learner characteristics. One of these characteristics is the learning styles (1).

Learning styles refer to the preferred way individual processes information and also describe a person's typical mode of thinking, remembering or problem solving (2). Researchers have identified three major learning styles: visual, auditory and kinesthetic. Visual learners use visual objects such as graphs, charts, pictures, and seeing information; auditory learners retain information through hearing and speaking; and kinesthetic learners like to use the hands-on tactile approach to learn new material (3).

Students can be easily identified and classified according to their learning styles, which indicates a domination of one learning styles. However, the same learner can have a mix of learning styles, meaning that he can learn the same things through different ways (4). 
The fact that learners differ in their way of learning have motivated educationists and teachers to think of different educational methodologies (5).

With the paradigm shift in the medical education field from the teacher-centred education to the student-centred learning, teachers' role has been changed from a source of information to a facilitator of learning $(6,7)$. This encouraged the educators to seek understanding of their students' learning styles in order to diversify the instructional methods and the learning activities to satisfy the different learning styles (8). Moreover, the harmonisation between the learners and educator in the facilitation process can be better if they share the same learning styles $(9,10)$.

During curriculum planning, the students' learning styles preferences can be the cornerstone in deciding on the content and the way that content would be transferred to and learned by the students. This can solve the monotonous way in dealing with different learners (11).

Ibn Sina National College for Medical Studies (ISNC) is the first private medical college under the supervision of the Saudi Ministry of Higher Education. It encompasses four health professions education programs. The Medicine program runs an integrated curriculum that has both systems-based modules and problem-based learning (PBL) and uses interactive lectures as the main teaching method.

At ISNC, a recent consideration has been paid as regards to the importance of learning style as a factor to improve the educational experience of learners. However, the ISNC is in the process of encouraging a shift to active learning, this requires more individualisation of instruction.

This study aims to explore ISNC students' learning styles, and determine what types of learners they are. This study will also determine the effect of related factors as gender, as well as making recommendations to improve teaching and learning at the ISNC.

\section{Method}

The Barsch Learning Styles Inventory is developed by Jeffrey Barsch (12), one of the quick assessments of learning styles. The inventory has 24 statements which are assigned values and these values are used in the scoring process. Three learning styles will be defined once the test is complete: Visual (sight), Auditory (sound), and Tactile/ Kinesthetic (small/large motor movements).

Barsch Learning Styles Inventory was used to assess the learning styles of the MBBS students at ISNC. A sample size of 550 students has been targeted. The overall response rate was $82.7 \%(\mathrm{n}=455)$. The students were asked to finish the inventory in one session after an awareness lecture and large group discussion about the characteristics and behaviours of different learning styles. The students were directed toward using the key at the end of the inventory to calculate the score and know their learning style. Completed inventories were then collected for further analysis in this study.

According to the classification criteria of Barsch Learning Styles Inventory, learners are classified as either dominantly Visual, Auditory or Kinesthetic according to the highest collective score they get in relation to the inventory questions representing that style. Scores have been manually calculated for each student and his/her learning style is indicated based on the inventory manual.

Ethical approval has been obtained from the Research Ethics Committee of ISNC prior to starting the research. Students were given the complete right to deny participation in the research. Also, students who participated were asked not to write their names or any indications to their identity.

\section{Data Analysis}

Data entry format has been created using Microsoft Excel 2010, and for the analysis of quantitative data, information was presented in tabular and graphic forms like bar and pie charts. Data analysis was performed 
using SPSS v.20. Descriptive analysis has been used (frequency and percentage). For comparing gender differences, $t$-test was used. Statistical significance was set at $p$-value $<0.05$.

\section{Results}

A total of 455 students $(46.8 \%$ males and $53.2 \%$ females) at Ibn Sina National College for Medical Studies completed the Barsch Learning Styles Inventory for determining the learning styles. Almost all of the students were Saudi $(95.4 \%)$, of the age group $<20$ years $(96.6 \%)$, and has no previous university education (98.7\%).

It was found that the visual learning style was the most prevalent learning style while the auditory was the least prevalent one among the studied sample.

Barsch's Visual Learning Style is the common style among the studies sample of students, both for males (59\%) and females $(61 \%)$. The least prevalent learning style is the Auditory Learning Style. There were minor differences between males and females in styles' prevalence. Those differences were not statistically significant $(p>0.05)$.

In a very small percentage of the study subjects $(3 \%)$, the scores for the three styles are very close to each other (one or two point's difference). We call this Tri-modal (VAK). The rest of the study population had two styles dominating the third one (Bimodal VK, VA or AK). No one in our sample was found to be purely of one style.

Table 1: Demographic data of the study sample

\begin{tabular}{lc}
\hline \multicolumn{1}{c}{ Response rate } & $\mathbf{4 5 5}$ out of $\mathbf{5 5 0}(\mathbf{8 2 . 7} \%)$ \\
\hline Gender & \\
Male & $213(46.8 \%)$ \\
Female & $242(53.2 \%)$ \\
Nationality & \\
Saudi & $434(95.4 \%)$ \\
Non-Saudi & $21(4.6 \%)$ \\
Age group & \\
$<20$ years & $440(96.6 \%)$ \\
$>20$ years & $15(3.4 \%)$ \\
School background & $348(76.5 \%)$ \\
Governmental & $107(23.5 \%)$ \\
Private & $6(1.3 \%)$ \\
Previous university education* \\
Yes \\
No
\end{tabular}

Note: Some of the students has been to some college/university (usually health-related programs) prior to joining Ibn Sina College. 
Table 2: Distribution of the study sample according to the dominant learning style group (according to the classification of Barsch")

\begin{tabular}{cccccc}
\hline \multirow{2}{*}{ Style } & \multicolumn{2}{c}{ Males } & \multicolumn{2}{c}{ Females } & \multirow{2}{*}{$\boldsymbol{p}$-value } \\
\cline { 2 - 5 } & No. & $\%$ & No. & $\%$ & \\
\hline Visual & 126 & 59 & 148 & 61 & 0.48 \\
Auditory & 38 & 18 & 46 & 19 & 0.72 \\
Kinesthetic & 49 & 23 & 48 & 20 & 0.53 \\
\hline
\end{tabular}

*The scores in the other two styles are not considered in this general classification.

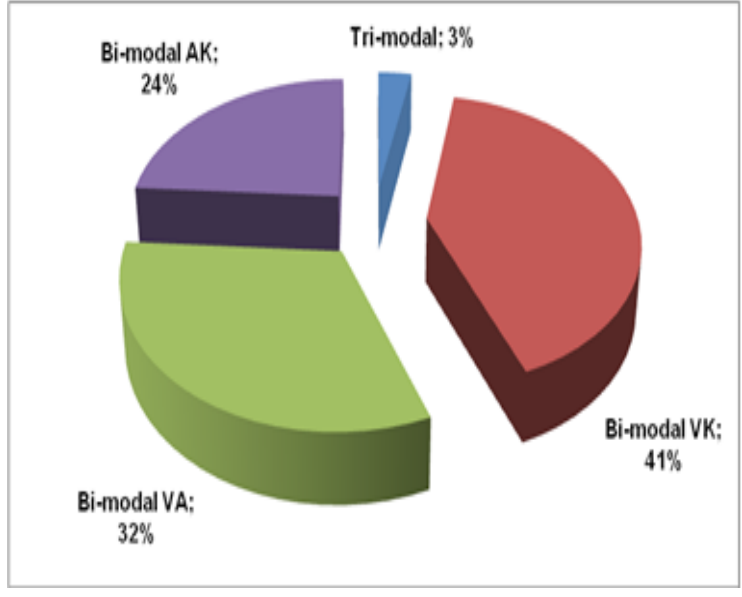

Figure 1: Proportions of the learners according to the mix of different styles.

Note: VK = Visual/Kinesthetic, VA = Visual/Auditory, $\mathrm{AK}=$ Auditory/Kinesthetic

\section{Discussion}

Knowing the learning style of students is a valuable skill in education. Knowledge of learning styles may help educators identify and solve learning problems among students, thus helping their students to become more effective learners and increase their academic performance (13). We found that our results are in congruence with Sabiha et al. (13) that was conducted among medical and dental students of first, second and third years in Islamabad University where we both found that the visual learning style was the predominant style in our study population. Similar to our results about the use of multiple styles, Nuzhat et al. (14) found that multiple learning styles of medical students represented $73 \%$ and Baykan \& Naçar (15) reported that $64 \%$ of first year medical students use multimodal learning style.

Our results match with a study held in a private university in Northern Cyprus, where the researchers reported that most of the students prefer visual learning style (41.7\%) (16). In contrast, Javadinia et al. (17) in Iran found that the learning style mostly used by these students was auditory $(48.6 \%)$. No one in our sample was found to be purely of one style. This was contradictory to a study held by Sabiha et al. (13) that was conducted among medical and dental students of first, second and third years in Islamabad University, where they found that the majority of medical and dental students had a single learning style, while only one sixth of medical and one third of dental students had multiple learning styles.

Javadinia et al. (17) found no significant relationship between the preferred learning styles and gender $(p=0.18)$. This is consistent with our results that show no statistically significant gender difference is observed. Also, Baykan \& Naçar (15) and Jill et al. (18) agreed with our results. On the contrary, Shah et al. (19) found that female students' preferred auditory learning style over other styles, while male students showed equal preference of auditory and kinesthetic learning style, and the difference between them was statistically significant.

\section{Conclusion}

The most prevalent learning style is the Visual one, which is in agreement with the 
literature on learning styles. The prevalence of different styles is similar in both males and females. Most importantly, medical students are not confined to only one learning styles, as they showed similar scores for two (bi-modal) or more (tri-modal). This agrees with the nature of medical students, who should be flexible in their mode of taking in information.

In response to such results, instructors should clearly address the diversity of learning styles among students and develop appropriate learning approaches. For example, more attention should be given to different educational activities (e.g. lectures) to make them more engaging to the students, through augmenting them with visual illustrations and multimedia.

\section{Acknowledgements}

The authors would like to thank the students of Ibn Sina National College (ISNC) for Medical Studies who participated in the study. Thanks also for the administration of the ISNC for their support.

\section{References}

1. Al Hamdani D. Exploring students' learning style at a Gulf University: a contributing factor to effective instruction. Procedia - Social and Behavioral Sciences. 2015;176:124-128.

2. Lucas M, Corpuz B. Facilitating learning: a metacognitive process. Metro Manila, Philippines: Lorimar Publishing, Inc.; 2007. p. 776 .

3. Abante $\mathrm{M}$, Almendral B, Manansala J, Mañibo J. Learning styles and factors affecting the learning of general engineering students. International Journal of Academic Research in Progressive Education and Development. 2014;3(1):16-27.
4. Lall M, Sharma S. Personal growth and training and developent. New Delhi: Excel Books; 2009.

5. Buxeda R, Moore D. Using learning styles data to design a microbiology course. Journal of College Science Teaching. 1999;29:159164.

6. Samarakoon L, Fernando T, Rodrigo C and Rajapakse S. Learning styles and approaches to learning among medical undergraduates and postgraduates. BMC Medical Education. 2013;13:42-45.

7. Isaac D. Global paradigm shift in medical education: issues of concern for Africa. Medical Teacher. 2007;29(9): 887-892.

8. Sinnerton T, Leonard L, Rogers K. Using learning style preferences to enhance the education and training of allied health professionals. The International Journal of Allied Health Sciences and Practice. 2014;12(1):1-5.

9. Laight DW. Attitudes to concept maps as a teaching/learning activity in undergraduate health professional education: influence of preferred learning style. Medical Teacher. 2004;26:229-233.

10. Armstrong E, Parsa-Parsi R. How can physicians' learning styles drive educational planning? Academic Medicine. 2005;80:680-684.

11. Fleming ND. I'm different; not dumb. Modes of presentation (VARK) in the tertiary classroom. In: Zelmer A, editor. Research and development in higher education, Proceedings of the 1995 Annual Conference of the Higher Education and Research Development Society of Australasia (HERDSA). 1995;18:308-313.

12. Barsch J. Barsch learning styles inventory. Novato, CA, USA: Academic Therapy Publications; 1991. 
13. Sabiha M, Shahina Yasmeen, Shabana Ali, Feroze Gallam. Students' learning styles require modified teaching strategies. Journal of Rawalpindi Medical College (JRMC). 2012;16(2):191-193.

14. Nuzhat A, Salem R, Mohammed S. Learning style preferences of medical students. International Journal of Medical Education. 2011;2:70-73.

15. Baykan Z, Naçar M. Learning styles of firstyear medical students attending Erciyes University in Kayseri, Turkey. Advances Physiology Education. 2007;31:158-160.

16. Özbaş S. The investigation of the learning styles of university students. The Online Journal of New Horizons in Education. 2013;3(1):53-58.
17. Javadinia S, Sharifzadeh G, Abedini M, Khalesi M, Erfanian M. Learning styles of medical students in birjand university of medical sciences according to VARK model. Iranian Journal of Medical Education. 2010;11(2):141-147.

18. Jill A, Heidi L, Stephen E. Does gender influence learning style preferences of firstyear medical students? Advances Physiology Education. 2007;31:336-342.

19. Shah C, Josho N, Mehta H, Gokhle P. Learning styles adopted by medical students. International Research Journal of Pharmacy IRJP. $2011 ; 2(12)$ : 227-229. 